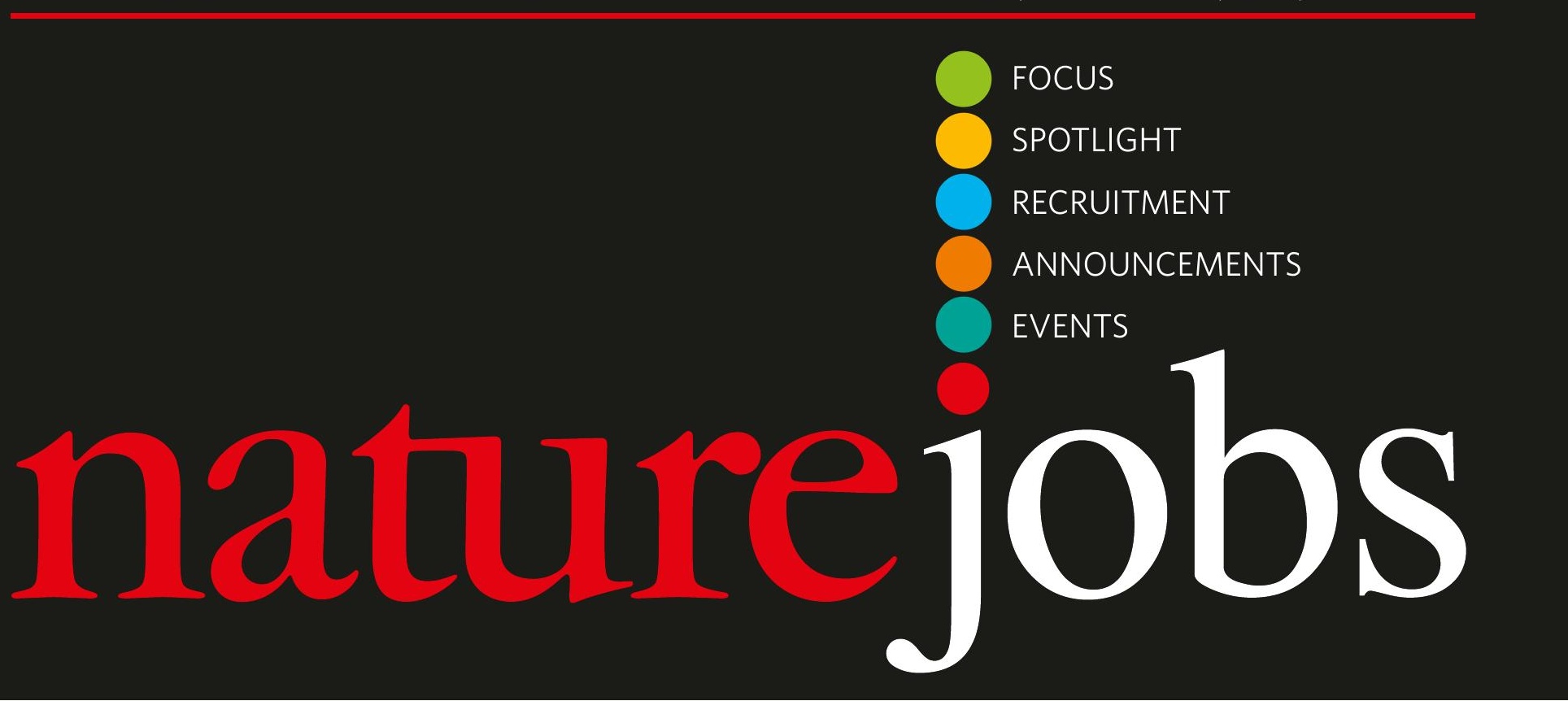

\title{
An infinite learning curve
}

Writer David Foster Wallace's most famous works, Everything and More and Infinite Jest, are concerned literally and metaphorically with infinity. Wallace sometimes describes himself as "ridiculously overeducated" - a description that many scientists, with years of postgraduate education and postdoctoral training under their belts, will recognize. Yet, like Wallace, these scientists still feel the need to learn more.

Of course, this desire can be sated by simply picking up a book to explore a different discipline. But in recent years more formal mechanisms for expanding education have begun emerging. These are helping scientists learn how to work across disciplines and often provide career workshops to give them off-the-bench skills.

One programme, run by the US National Institutes of Health, trains chemists, engineers, physicists and mathematicians in biological research. Since it launched in 2000, more than 120 mid-career scientists have gone back to the classroom to pursue years of additional coursework. Members of its first class are now ready to combine their physical background with a newfound biological education, which should make them more effective interdisciplinary researchers (see page 470).

Another programme, run by the US-based Committee on the Advancement of Women Chemists (see page 592), offers workshops to help female chemists and engineers leap gender hurdles. These courses emphasize communication, leadership and negotiation skills. So far the workshops have proved to be a big success with participants and, as a result, the organization is considering expanding its reach to Europe.

The interest in both of these programmes shows that there is nothing ridiculous about education beyond the PhD and postdoc. Whether skills are scientific or off-the-bench, in today's competitive environment, the need to learn more seems to go on and on, ad infinitum.

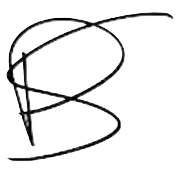

\section{Paul Smaglik, Naturejobs editor}

European Head Office, London

The Macmillan Building,

4 Crinan Street,

London N19XW, UK

Tel: +44 (0) 2078434961

Fax: +44 (0) 2078434996

e-mail:naturejobs@nature.com

Naturejobs Sales Director: Nevin Bayoumi (4978) European Sales Manager: Andy Douglas (4975)

Classified Sales Representative:

Michaela Bjorkman

West USA/West Corp. Canada

225 Bush Street, Suite 1453

San Francisco, CA 94104

Tel: +14157813803

Fax: +14157813805

e-mail:m.bjorkman@naturesf.com
Naturejobs web development: Tom Hancock Naturejobs online production: Niamh Shields

European Satellite Office

Patrick Phelan

e-mail:p.phelan@nature.com

Japan Head Office, Tokyo

Chiyoda Building,

2-37 Ichigayatamachi,

Shinjuku-ku,

Tokyo 162-0843

Tel: +81332678751

Asia-Pacific Sales Director: Rinoko Asami

e-mail: r.asami@naturejpn.com
Fax: +81332678746 